\title{
ANODE HEEL EFFECT ATTENUATION IN LUMBAR SPINE RADIOGRAPHY: CAN THE USE OF ALUMINIUM FILTERS IMPROVE THE CLINICAL PRACTICE OF RADIOGRAPHERS?
}

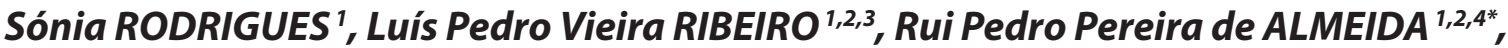 \\ António Fernando Caldeira Lagem ABRANTES ${ }^{1,2,4}$, Kevin AZEVEDO ${ }^{1,2,4}$, Oksana LESYUK ${ }^{1}$, \\ Joana SOARES ', Rúben DORES ' , João ALEIXO ${ }^{1}$, Patrick SOUSA ${ }^{1,2}$ \\ 1 University of Algarve, School of Health, Department of Medical Imaging and Radiotherapy, Campus de Gambelas, 8005-139 \\ Faro, Portugal. \\ 2 CES - ESSUALG (Center for Studies and Development in Health), Faro, Portugal \\ 3 CIDAF (Research Unit for Sport and Physical Activity), Coimbra, Portugal \\ ${ }^{4}$ CICS.NOVA.UÉvora (University of Évora, Interdisciplinary Centre of Social Sciences), Évora, Portugal
}

Corresponding author: rpalmeida@ualg.pt

Received: 23.11 .2020

Accepted: 30.12 .2020

https://doi.org/10.47724/MIRTJ.2020.i02.a003

\begin{abstract}
Purpose: The aim of this study was to design an aluminiumbased filter to reduce the anode heel effect in lumbar spine radiographs.

Methods: Initially, lumbar spine examinations were observed in a public imaging department to determine standard exposure parameters. Then, the characterization of the anode heel effect was made using the Unfors Xi R/F detector and, based on the data collected, aluminium filters were designed with a wedge shape and thicknesses ranging from 0.1 to $4.0 \mathrm{~mm}$. The assessment of the entrance skin dose (ESD) reduction was performed on the anthropomorphic phantom with and without filters, using the universal dosimeter UNIDOS E equipped with an ionization chamber. Finally, the image quality assessment was performed with the Pehamed Phantom Digrad A+K and image quality surveys were applied to radiographers and radiologists.
\end{abstract}

Results and Discussion: Uniformity of the beam was achieved, especially with filter number 2, which presents a significant variation of $9 \%$ between the cathodic and anodic side. This filter contributes to ESD reduction of $35 \%$ and $36 \%$ for AP and lateral projection, respectively. Also, according to radiographers and radiologists, it improves the image quality of lumbar spine radiography.

Conclusion: The use of aluminium filters can be advantageous in the clinical practice of radiographers when performing lumbar spine radiographs since it allows the standardization of the anode heel effect, reduces the radiation dose to the patient and does not compromise image quality.

Keywords: anode heel effect, aluminium filters, image quality, radiation protection, radiographers, entrance skin dose. 


\section{INTRODUCTION}

Healthcare is a fundamental human right and is considered to be of major importance for global development as it is crucial for enhancing the quality of life and extending life expectancy (1). Rather than being only involved in primary care, healthcare has evolved and follows social trends, thus striving for quality and excellence. That is why healthcare services have become increasingly accessible, with a corresponding increase in the number of imaging examinations.

Medical imaging procedures have been playing a key role in current medical care through their use in a variety of modalities. However, those using $x$-ray have the disadvantage of the radiation dose received by patients and its potential harms. This may be reduced through technological development, scientific research, and proper use of equipment (2).

Due to the risks of radiation exposure and a gradual increase in the number of examinations, reducing the exposure dose to the patient without decreasing diagnostic image quality should be a primary concern.

In the imaging field, the aim is to provide a diagnostic examination with maximum image quality, while keeping the radiation levels as low as possible (ALARA principle) (3). In this sense, there are several parameters that can easily be adjusted, which allows a balance between patient radiation dose and image quality, such as the voltage (kV), the exposure currenttime product (mAs), the source-to-image receptor distance (SID) and the proper use of collimators. However, there are other factors that can also interfere with image quality that are not possible to control, such as the anode heel effect (4). This effect is defined as "the lower field intensity towards the anode in comparison to the cathode due to lower $x$-ray emissions from the target material at angles perpendicular to the electron beam" (5). Physical aspects of the construction of the x-ray tube combined with the physical properties of the x-ray radiation cause a nonuniformity of the beam intensity along the anode-cathode axis known as the anode heel effect. The intensity of the radiation emitted at the cathode side is higher than at the anode side. In most radiographic examinations, the radiographer can naturally compensate this effect and take advantage of it by positioning the patient's thicker region at the cathode end. This contributes to obtaining optimal exposures for certain anatomical structures, although it does not completely cancel out the effect and changes in the image quality remain (2).

In mammography modality, the x-ray machine features specific aluminium filters to remove non-useful low intensity $\mathrm{x}$-rays and to enhance contrast sensitivity (4). It also presents a considerable anodic heel effect due to the anode target angle and short SID (6). Thus, in order to take maximum advantage of this effect, the cathode side is positioned at the chest wall. Incorrect use of this effect in radiographic examinations may result in cathode side overexposure and underexposure on the anode side, decreasing the image quality (7-12). For this reason, issues such as $\mathrm{x}$-ray beam intensity assessment, $\mathrm{x}$-ray beam standardization, dose reduction at patient entrance, and image quality have been continuously under study.

There are recent studies that investigate the influence of the anode heel effect in different anatomical regions that present a greater density divergence along the tube axis (cathode to anode $(7,8,13)$. However, since there is little evidence regarding the attenuation of this effect in lumbar spine radiography, the aim of this research was to evaluate the attenuation of anode heel effect in the lateral lumbar spine examination using a customized aluminium filter, as well as to assess the ESD and image quality.

\section{METHODS}

In the first step, an assessment of the baseline exposure parameters for the lumbar spine radiography was conducted. Then, anode heel effect was evaluated and data for the design and construction of a customized filter were gathered. Finally, the viability of the filter, ESD and image quality were assessed.

\section{Step 1: Determination of exposure parameters for lumbar spine examination}

A survey of the exposure parameters used to perform the lateral lumbar spine examination in a digital radiology imaging room (Philips x-ray tube SRO 2550 ROT 350) from a public hospital was applied. Data collected included the following parameters: $k \mathrm{~V}$, $\mathrm{mAs}$, the selection of the automatic exposure control (AEC) mode, room configuration, $x$-ray field size at image receptor and SID.

\section{Step 2.1: Measurement of the beam intensity along the longitudinal anode- cathode axis}

Exposure rates were measured along the longitudinal anodecathode axis, using the Unfors Ray Safe Xi detector based on a solid-state sensor, in order to plot the distribution of radiation intensity. The mean values of $\mathrm{kV}$ collected in step 1 were used, and the $\mathrm{mAs}$ value was decreased to $1 \mathrm{mAs}$ to prevent X-ray tube overheating due to the high number of exposures. Room configuration and SID were reproduced. The centre of the exposure field was defined as the zero position and all measured values in the cathode direction were considered to correspond to the negative axis and in the direction of the anode to the positive axis. Several measurements were made with an increment of $1 \mathrm{~cm}$ along the longitudinal field length.

\section{Step 2.2 - Uniformization of the beam intensity distribution along the longitudinal anode-cathode axis}

In order to uniformize the distribution of the beam intensity, the minimum value of the exposure rate obtained in the previous step was taken as the reference value. Again, several measurements were repeatedly made with an increment of $1 \mathrm{~cm}$ and adding aluminium half-value length (HVL) filters ( $99.5 \%$ of purity) on top of the detector until the exposure rate values reach the reference value, thus counteracting the behaviour of the anode heel effect. At the same time, the required aluminium thickness values were obtained at each longitudinal axis position for subsequent filter design. The thickness of the aluminium HVL filters ranged from $0.1 \mathrm{~mm}$ to $4.0 \mathrm{~mm}$. Exposure rate was measured along the longitudinal anode-cathode axis in order to plot the filter design. 


\section{Step 2.3: Aluminium filter construction}

In this step, the technical drawing for the filter construction was carried out using Autodesk AutoCAD 210. Since the measurements were taken on top of the patient table, it was necessary to scale it to attach the filter to the bottom of the collimator assembly. To design the filter, a $4.0 \mathrm{~mm}$ thick aluminium plate, alloy 2024 (T351) with a purity of $91 \%$ to $95 \%$, was used. Due to budgetary constraints, it was not possible to match the aluminium purity of this plate with the HVL filters used in the previous step, knowing that this difference would have an impact on the results (10). Regarding the cut of the aluminium plate, two samples were manufactured by CNC turning in two different mechanical workshops facilities that specialized in this type of procedure.

\section{Step 3.1: Evaluation of the anode heel effect behaviour}

Measurements from the first step were repeated without a filter and then with each filter sample attached to the bottom of the collimator assembly to check the effect of the filters regarding the beam intensity distribution along the longitudinal anodecathode axis. All previous configurations were reproduced.

\section{Step 3.2: Evaluation of the ESD reduction}

In order to evaluate the ESD on the phantom with and without filters, three exposures for each type of examination were carried out with an ionization chamber placed on top of the phantom in the centre of X-ray field. An important consideration in this work is that ESD is obtained directly from the measurement of the transmitted radiation through the double-faced plane-parallel ionization chamber, which is in contact with the tissue-equivalent phantom, measuring the incident radiation as well as backscatter radiation.

\section{Step 3.3: Image Quality Assessment}

Three exposures were performed to assess the image quality using the Pehamed Phantom Digrad A+K. Spatial resolution, grey scale and contrast level were evaluated with this phantom, at SID of $100 \mathrm{~cm}$ and the size of the x-ray field was adjusted to the phantom.

Then, a survey was distributed to the radiologists and radiographers of the imaging department to assess the subjective image quality, using the European Guidelines on image criteria for lumbar spine examinations and a visual grading analysis $(14,15)$. The survey included images obtained on the anthropomorphic phantom, with a total of twenty questions.

\section{RESULTS}

\section{Determination of exposure parameters for lumbar spine examination}

The results obtained from the exposure parameters survey of the AP and Lateral Lumbar spine radiographs were as follows: the use of AEC mode, without additional filtration, SID of 100 $\mathrm{cm}$, source-table distance of $90.2 \mathrm{~cm}$, the size of the $x$-ray field on top of the table of $40 \mathrm{~cm} \times 20 \mathrm{~cm}$, large focus, and a voltage of 85 (AP) and $90 \mathrm{kV}$ (Lateral).

\section{Measurement of the beam intensity along the longitudinal anode-cathode axis}

It is known that the variation of the anode heel effect in terms of relative intensity can vary between $75 \%$ to $120 \%$ along the longitudinal anode-cathode axis (3). In this study, as expected, the $x$-ray beam is less intense on the anode side and more intense on the cathode side. A variation of the relative exposure rate up to $58 \%$ occurs (Figure 1 ).

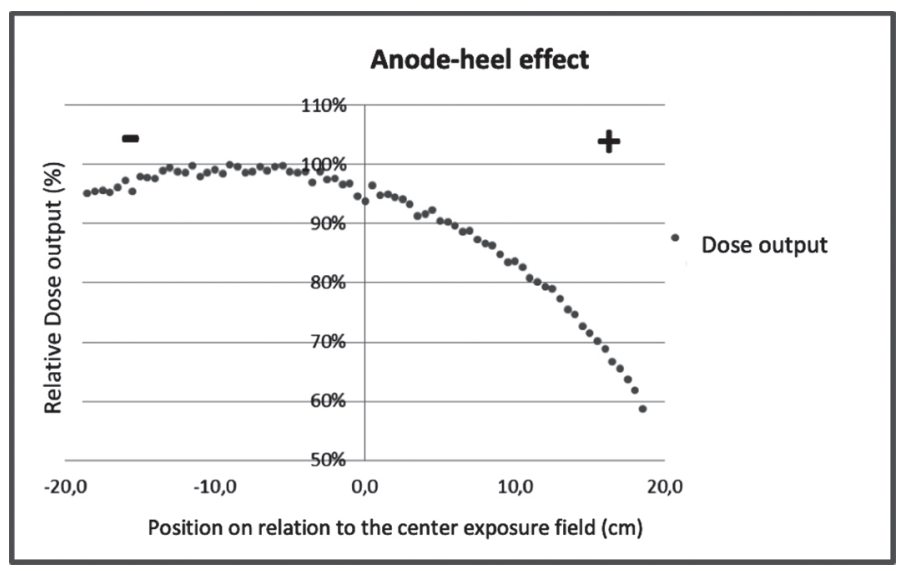

Figure 1: X-ray beam intensity variation (\%) as a function of the position in relation to the center of the exposure field

\section{Uniformization of the beam intensity distribution along the longitudinal anode-cathode axis}

The thickness of the aluminium required to compensate the beam intensity distribution along the cathode-anode axis was measured and presented in Figure 2. As expected, higher aluminium thickness is needed on the cathode side. Step lines of equal aluminium thickness on this side are visible because the minimum HVL thickness of aluminium filters available for increment was $0.1 \mathrm{~mm}$.

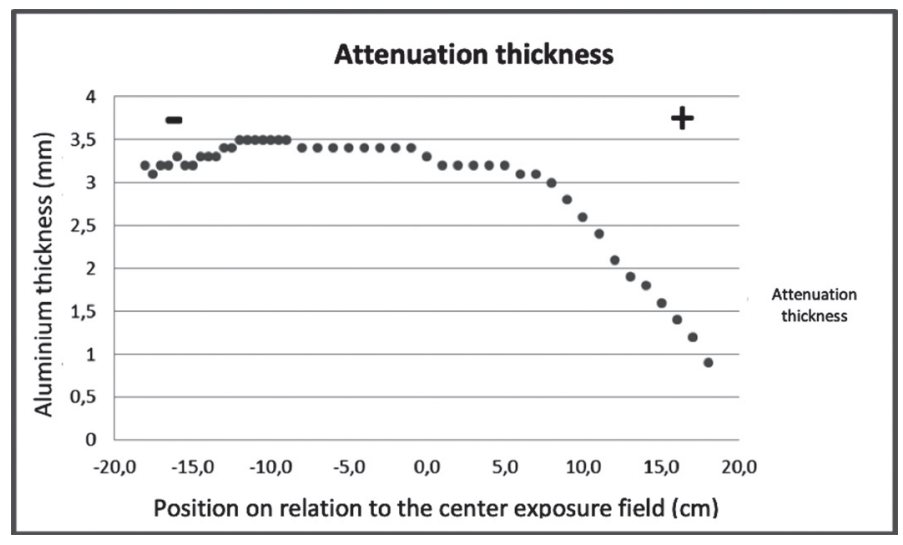

Figure 2: aluminum thickness required to attenuate the intensity of the beam in order to compensate the anode heel effect 


\section{Aluminium filter construction}

Based on Figure 2, a technical drawing was made scaling the length of the beam at the patient table to the length of the output of the collimator assembly. Two filters were constructed, filter 1 (Figure 3) and filter 2 (Figure 4).

\section{Cut AA}
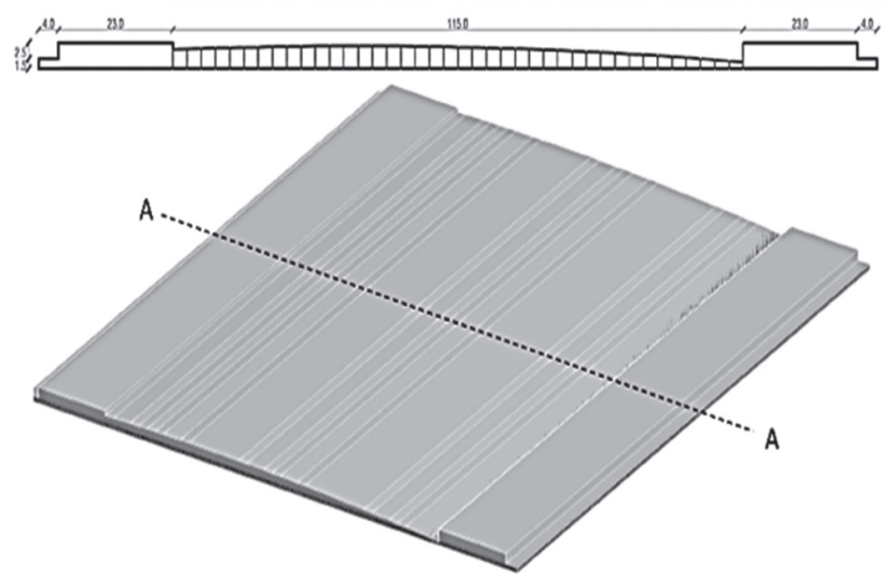

Figure 3: Technical drawing of aluminium filter 1. Top image refers to the cross-sectional view of the piece represents three-dimensional in the image below

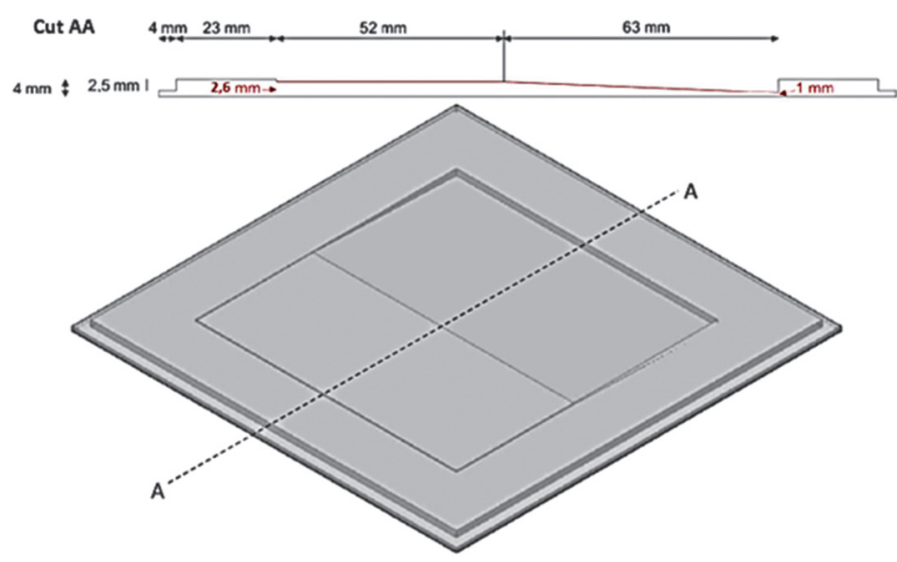

Figure 4: Technical drawing of the aluminium filter 2. Top image refers to the cross-sectional view of the piece represents three-dimensional in the image below

\section{Evaluation of the anode heel effect behaviour}

Exposure and dose rates were measured along the longitudinal anode-cathode axis in order to plot the radiation intensity distribution in different configurations: with no filter, with filter 1 and with filter 2, as presented in Table 1. Figure 5 shows the radiation exposure variation along the longitudinal anode-cathode axis at the patient table in the mentioned configurations.

Considering the results obtained with filter 1 , a uniformization of the x-ray beam intensity on the cathode side can be observed, and from the central position of the exposure field to the edge of the anode side, the values increase gradually.

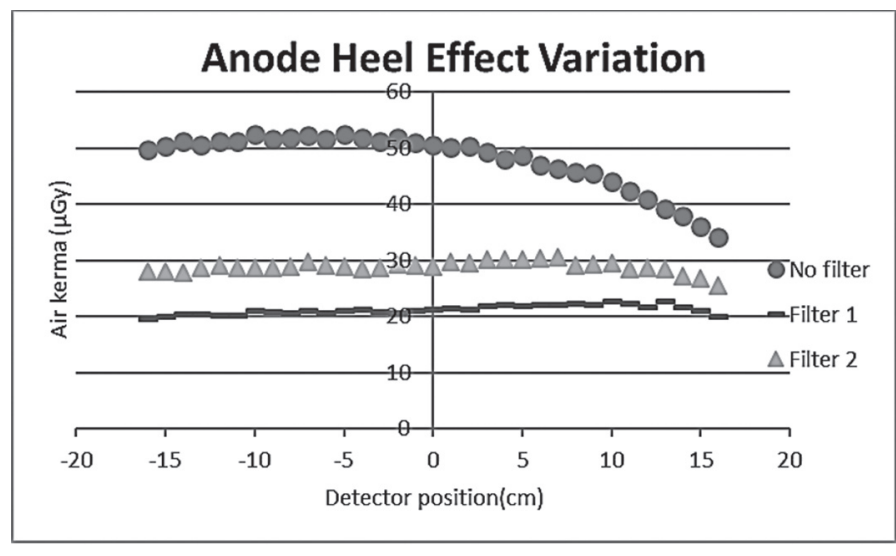

Figure 5: Anode Heel Effect variation without and with filters 1 and 2

There is a significant variation of $17 \%$ between both cathode and anode sides.

With filter 2, the same observation can be made, although with a variation of $9 \%$ between both cathode and anode sides. Thus, with the use of both filters, an almost complete uniformity of the x-ray beam can be observed. Small variations are the result of the difference in the aluminium purity.

\section{Evaluation of the ESD reduction}

It is possible to observe an ESD reduction in the AP and lateral projection of the lumbar spine, with the use of both filters compared to the examination performed without a filter. As seen in Figure 6, the ESD values in AP projection were 67.6 $\mu \mathrm{Gy} ; 36.9 \mu \mathrm{Gy}$ and $43.6 \mu \mathrm{Gy}$ for the configurations without a filter, with filter 1 and with filter 2, respectively. The lateral projection values were 109.2 $\mu \mathrm{Gy} ; 57.1 \mu \mathrm{Gy}$ and $69.6 \mu \mathrm{Gy}$,

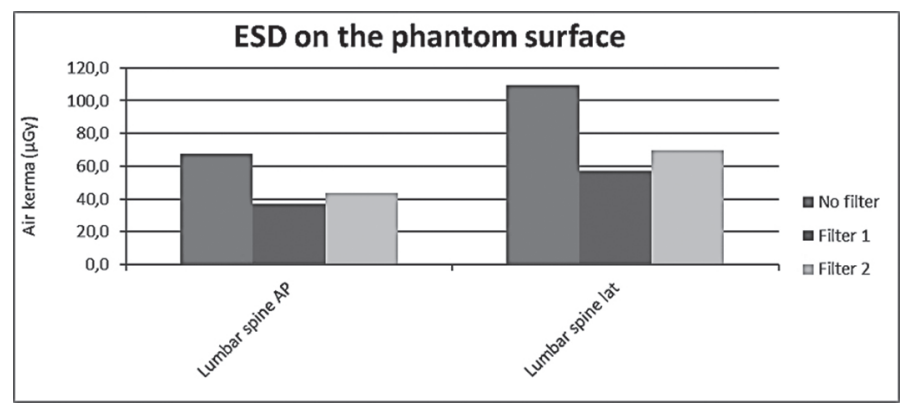

Figure 6: ESD values on the phantom surface

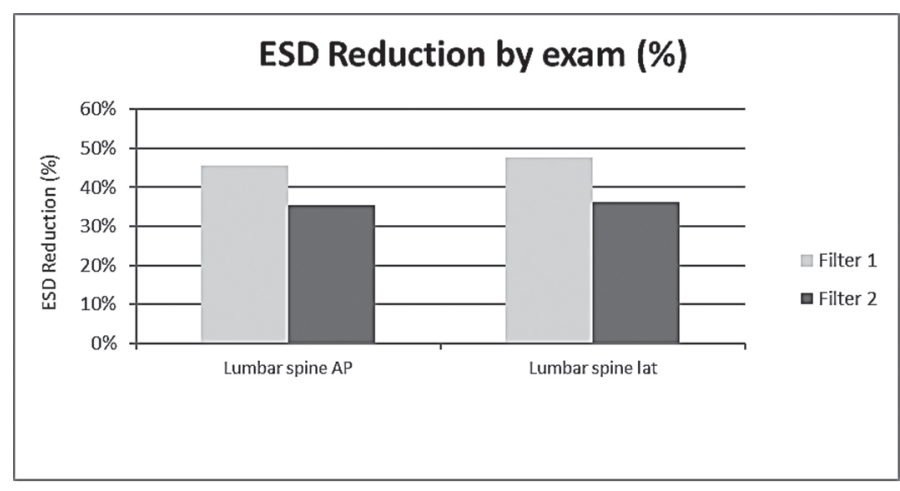

Figure 7: Percentage of ESD Reduction on the phantom 
Table 1: Radiation intensity distribution along the longitudinal anode-cathode axis in three different configurations: with no filter, with filter 1 and with filter 2

\begin{tabular}{|c|c|c|c|c|c|c|}
\hline \multirow{2}{*}{$\begin{array}{l}\text { Detector position in function } \\
\text { of FOV centre }(\mathrm{cm})\end{array}$} & \multicolumn{3}{|c|}{ Exposure $(\mu G y)$} & \multicolumn{3}{|c|}{ Dose rate $(\mu G y / s)$} \\
\hline & No filter & Filter 1 & Filter 2 & No filter & Filter 1 & Filter 2 \\
\hline-20 & 47.54 & 19.56 & 26.66 & 22.51 & 10.35 & 13.33 \\
\hline-19 & 47.36 & 19.30 & 27.07 & 23.68 & 10.22 & 13.53 \\
\hline-18 & 49.01 & 19.39 & 26.75 & 23.21 & 10.91 & 14.16 \\
\hline-17 & 48.91 & 19.37 & 27.67 & 24.45 & 10.89 & 13.83 \\
\hline-16 & 49.81 & 19.65 & 27.96 & 23.59 & 10.40 & 13.98 \\
\hline-15 & 50.31 & 19.99 & 27.94 & 23.83 & 10.58 & 13.97 \\
\hline-14 & 51.20 & 20.42 & 27.89 & 24.25 & 10.81 & 14.77 \\
\hline-13 & 50.64 & 20.38 & 28.61 & 23.99 & 10.79 & 14.30 \\
\hline-12 & 51,31 & 20.25 & 29.09 & 24.30 & 10.72 & 14.54 \\
\hline-11 & 51.12 & 20.31 & 28.74 & 25.56 & 10.75 & 14.37 \\
\hline-10 & 52.44 & 21.04 & 28.70 & 24.84 & 11.14 & 15.19 \\
\hline-9 & 51.72 & 20.89 & 28.66 & 25.86 & 11.06 & 15.17 \\
\hline-8 & 51.83 & 20.73 & 28.93 & 25.91 & 10.97 & 14.46 \\
\hline-7 & 52.28 & 21.07 & 29.62 & 24.76 & 11.15 & 14.81 \\
\hline-6 & 51.62 & 20.59 & 29.17 & 25.81 & 10.90 & 14.58 \\
\hline-5 & 52.50 & 21.12 & 28.87 & 24.87 & 11.18 & 15.28 \\
\hline-4 & 51.77 & 21.27 & 28.50 & 25.88 & 11.26 & 15.09 \\
\hline-3 & 51.25 & 20.84 & 28.69 & 25.62 & 11.03 & 15.19 \\
\hline-2 & 51.75 & 20.64 & 29.29 & 24.51 & 11.61 & 14.64 \\
\hline-1 & 51.02 & 21.10 & 29.17 & 24.17 & 11.17 & 14.58 \\
\hline 0 & 50.65 & 21.21 & 28.93 & 23.99 & 11.23 & 15.32 \\
\hline 1 & 50.17 & 21.59 & 29.68 & 23.76 & 11.43 & 15.71 \\
\hline 2 & 50.44 & 21.27 & 29.55 & 23.89 & 11.26 & 14.77 \\
\hline 3 & 49.42 & 21.88 & 30.18 & 23.41 & 11.58 & 15.09 \\
\hline 4 & 48.05 & 22.10 & 30.06 & 24.02 & 11.05 & 15.03 \\
\hline 5 & 48.61 & 21.96 & 30.18 & 23.02 & 11.62 & 15.09 \\
\hline 6 & 46.97 & 22.07 & 30.28 & 23.48 & 11.68 & 15.14 \\
\hline 7 & 46.36 & 22.23 & 30.47 & 23.18 & 11.77 & 15.23 \\
\hline 8 & 45.65 & 22.36 & 29.08 & 22.82 & 11.84 & 15.39 \\
\hline 9 & 45.54 & 22.05 & 29.32 & 21.57 & 11.67 & 14.66 \\
\hline 10 & 44.00 & 22.73 & 29.60 & 22.00 & 11.36 & 14.80 \\
\hline 11 & 42.46 & 22.27 & 28.44 & 21.23 & 11.13 & 15.05 \\
\hline 12 & 40.80 & 21.67 & 28.59 & 20.40 & 11.47 & 14.29 \\
\hline 13 & 39.17 & 22.67 & 28.55 & 19.58 & 11.33 & 14.27 \\
\hline 14 & 37.91 & 21.78 & 27.14 & 18.95 & 11.53 & 14.36 \\
\hline 15 & 36.12 & 21.09 & 26.79 & 17.11 & 11.16 & 13.39 \\
\hline 16 & 34.06 & 20.05 & 25.43 & 16.13 & 10.61 & 13.46 \\
\hline 17 & 30.49 & 19.33 & 23.29 & 15.24 & 10.23 & 11.64 \\
\hline 18 & 27.14 & 18.30 & 21.75 & 13.57 & 9.693 & 10.87 \\
\hline 19 & 23.57 & 16.35 & 18.36 & 11.78 & 8.660 & 9.720 \\
\hline 20 & 17.98 & 12.66 & 14.60 & 8.994 & 6.706 & 7.729 \\
\hline
\end{tabular}


respectively. Therefore, as displayed in Figure 7, a reduction of $45 \%$ was observed with filter 1 in AP projection and $48 \%$ in lateral projection, and lower rates are illustrated with the use of filter 2 (35\% and 36\%, respectively).

\section{Image Quality Assessment}

Dynamic range, spatial resolution and low contrast detectability were tested with the phantom for the same configurations. The results are presented in Table 2. No significant differences were identified between the images with filter 2 and without a filter. Filter 1 presented a higher dynamic range and a better contrast of images, but a lower spatial resolution for diagnostic images.

Table 2: Results from the image quality assessment with Pehamed Phantom Digrad $A+K$

\begin{tabular}{|l|c|c|c|}
\cline { 2 - 4 } \multicolumn{1}{c|}{} & No Filter & Filter 1 & Filter 2 \\
\hline Dynamic range & 6 & 7 & 6 \\
\hline Spatial resolution (Lp/mm) & 2.8 & 2.5 & 2.8 \\
\hline Low contrast detectability & $0.8 \%$ & $0.8 \%$ & $0.8 \%$ \\
\hline
\end{tabular}

To assess the subjective image quality, a total of 30 questionnaires were obtained from radiologists and radiographers of the imaging department. Based on the visual grading analysis, $22 \%$ of them considered that the images without a filter had better quality and $49 \%$ preferred the images obtained with filter 1 . The remaining $29 \%$ identified no differences in image quality.

\section{DISCUSSION}

In this study, the exposure parameters adopted for the examination of the lumbar spine experiments were reproduced from the actual conditions used at the department where the research was conducted, and it was found that they are in accordance with the European Guidelines on Quality Criteria for Diagnostic Radiographic Images, as well as similar studies (15-16).

The observed anode heel effect allowed a verification of a variation of $58 \%$ in beam intensity along the longitudinal anode-cathode axis. Similar results were obtained by Gilboy with a variation of $55 \%$ (4). Also, Terry et al. have investigated the non-uniformity of the x-ray beam and they found a decrease of $16 \%$ to $40 \%$ in the radiation intensity along the anode-cathode (18). It is well known that the appropriate use of this effect can reduce the effective dose to patients in some common radiological examinations. However, due to the anatomy of the lumbar spine in most patients, the use of specific filters can enable a uniformity of the radiation beam (19-21).

Aluminium alloy 2024 (T351) was used in this study for the design of the filters, which is a cheap material easily found on the market, but it has a lower aluminium purity than the HVL aluminium filters used to determine the radiation attenuation thickness along the anode-cathode longitudinal axis. This is the main limitation of the study due to financial constraints. The results obtained with filter 1 were not satisfactory considering a maximum variation of the x-ray beam intensity of $17 \%$, since a maximum variation of $10 \%$ was expected.
These results are mostly related to the fact that the purity of the aluminium used for filter manufacturing is low (between $91 \%$ and $95 \%$ ) compared to the purity of HVL aluminium filters (99.5\%). The aluminium alloy 2024 (T351) includes $3.8 \%$ to $4.9 \%$ copper as the primary alloying element, and since copper has much higher density than aluminium, this may explain the obtained results. As mentioned above, filter 2 was designed and built under different conditions than filter 1 , due to budget limitations, and a maximum variation of the intensity of the x-rays of $9 \%$ was reached, as initially intended. The ESD reduction with filter 1 was higher than with filter 2 due to the larger thickness of aluminium. A reduction of $45 \%$ and $48 \%$ was observed in AP and Lateral projection, respectively, and lower rates were obtained using filter 2 (35\% and $36 \%$ ). These results are more favorable to those obtained by Fung and Gilboy, where they only assessed the patient's position in relation to the cathode-anode axis, obtaining ESD variations between $12 \%$ to $26 \%$ (4). In the study by Karami et al, no meaningful difference was found for the measured ESD of pelvis radiography between two groups of patients (anode directed toward the feet of patients, compared to the patients in which the anode was directed toward the head) (22). A reduction on the effective dose (from $0.022 \mathrm{mSv}$ to $0.002 \mathrm{mSv}$ ) was achieved by Lai et al. using $0.3 \mathrm{~mm}$ Cu filter in the lateral lumbar spine radiography, maintaining image quality (23). However, since the dose optimization techniques for the routine AP and Lateral lumbar spine projection have not been fully explored in the current literature, it was possible to verify that the use of specific filters can be effective. In addition, other studies revealed ESD values higher than those obtained in the present study, also indicating a good adequacy of the technical exposure parameters $(4,17,24)$.

Regarding the evaluation of the image quality of the radiographs, the results obtained were positive and thus support the use of a filter when performing lumbar spine radiographs in the clinical practice of radiographers. Since the diagnostic value of the radiographic images is highly dependent on the image quality, it was possible to successfully observe the image quality control tests for the dynamic range, spatial resolution and low contrast detectability, similarly observed in other studies $(23,25,26)$.

\section{CONCLUSION}

It has been proven that both aluminium filters reduced the anode heel effect, achieving better uniformity of the beam with filter 2 ( $9 \%$ variation).

The use of filters is beneficial for patients in this kind of procedure and is in compliance with the ALARA principle since a significant reduction in ESD was obtained for both filters, without compromising the image quality.

Thus, based on this study, it is recommended that radiographers from this imaging department consider using such filters when performing lumbar spine radiographs.

\section{Acknowledgments}

We would like to thank the European Society of Radiology for the opportunity to present the preliminary and partial results of this study at the European Congress of Radiology in Vienna, Austria. 
Also, we would like to thank to GyRrad (spin-off company from University of Algarve) for providing dosimetric support material and for assisting in the filters design.

\section{REFERENCES}

1. Soares F, Pereira A, Flôr R. Utilização de vestimentas de proteção radiológica para redução de dose absorvida: uma revisão integrativa da literatura. Radiologia Brasileira. 2011;44:97-103. Available from: https://doi.org/10.1590/ S0100-39842011000200009

2. Lima F. Técnicas de diagnóstico com raios-x: aspetos físicos e biofísicos. 2nd ed. Coimbra; 2009. Available from: https://doi.org/10.14195/978-989-26-0484-8

3. Bushong S. Radiologic Science for Technologists: Physics, Biology and Protection. 11th ed. Mosby; 2017. eBook ISBN: 9780323429443

4. Fung K, Gilboy, W. "Anode heel effect" on patient dose in lumbar spine radiography. Br. J. Radiol. 2000;73:531-6. Available from: https://doi.org/10.1259/ bjr.73.869.10884750

5. Curry T, Dowdey E, Murry R. Christensen's physics of diagnostic radiology. 4th ed. Lippincott Williams \& Wilkins; 1990. ISBN:0812113101.

6. Kim G, Lee R. Effect of Target Angle and Thickness on the Heel Effect and X-ray Intensity Characteristics for 70 kV X-ray Tube Target. Progress in Medical Physics. 2016;27(4):272-276. Available from: https://doi. org/10.14316/pmp.2016.27.4.272

7. Mraity H, Walton L, England A, Thompson J, Lança L, Hogg $P$. Can the anode heel effect be used to optimise radiation dose and image quality for AP pelvis radiography? Radiography. 2020;26(2):e103-e108. Available from: https://doi.org/10.1016/j.radi.2019.11.094

8. Harding L, Manning-Stanley A, Evans P, Taylor E, Charnock $P$, England A. Optimum patient orientation for pelvic and hip radiography: A randomised trial. Radiography. 2014;20(1):22-32. Available from: https:// doi.org/10.1016/j.radi.2013.09.002

9. Lima N, Hoff, G. Impacto da pureza dos filtros de alumínio no valor de Camada Semi-Redutora em radiologia convencional e mamografia. Brazilian J. Radiat. Sci. 2016;3 (2A):1-13. Available from: https://doi.org/10.15392/bjrs. v3i2A.92

10. Behrman R, Yasuda G. Effective dose in diagnostic radiology as a function of x-ray beam filtration for a constant exit dose and constant film density. Med. Phys. 1998;25:780-790. Available from: https://doi. org/10.1118/1.598260
11. Behrman R. The impact of increased Al filtration on x-ray tube loading and image quality in diagnostic radiology. Med Phys. 2003;30(1),69-78. Available from: https://doi. org/10.1118/1.1528180

12. Daud N, Ali M, Nazri N, Hamzah N, Awang N. The effect of compensating filter on image quality in lateral projection of thoraco lumbar radiography. Journal of Physics: Conference Series. 2014; 546. Available from: https://doi. org/10.1088/1742-6596/546/1/012002

13. Effendi M, Fatimah R, Sholeh A, FatchurohmahW. Design of the aluminum compensating filter to improve the image quality in the lateral projection of lumbosacral vertebrae. AIP Conference Proceedings 2094. 2019; 020018. Available from: https://doi.org/10.1063/1.5097487

14. Almén A, Tingberg A, Mattsson S, Besjakov J, Kheddache $S$, Lanhede B, Mansson L, Zankl M. The influcence of different technique factors on image quality of lumbar spine radiographs as evaluated by established CEC image Criteria. The British Journal of Radiology. 2000;73,11921199.

15. European Commission. European Guidelines on Quality Criteria for Diagnostic Radiographic Images. Luxembourg: Office for Official Publications of the European Communities. 1996. Available from: https:// www.sprmn.pt/pdf/EuropeanGuidelineseur16260.pdf

16. Ofori E, Ofori-Manteaw B, Gawugah J, Nathan J. Relationship between Patient Anatomical Thickness and Radiographic Exposure Factors for Selected Radiologic Examinations. Journal of Health, Medicine and Nursing. 2016;23,150-162. Available from: https://core.ac.uk/ download/pdf/234691718.pdf

17. Sharma R, Sharma S, Pawar S, Chaubey A, Kantharia $S$, Babu D. Radiation dose to patients from X-ray radiographic examinations using computed radiography imaging system. Journal of Medical Physics. 2015;40(1)2937. Available from: https://www.jmp.org.in/article. asp?issn=0971-6203; year $=2015 ;$ volume $=40 ;$ issue $=1 ;$ spa ge=29;epage=37;aulast $=$ Sharma

18. Terry J, Waggner R, Blough A. Half-value and intensity variations as a function of position in the radiation field for film-screen mammography. Med Phys. 1999;26:259266. Available from: https://doi.org/10.1118/1.598513

19. Cowen A, Brettle D, Workman A. Technical note: Compensation for field non-uniformity on a mammographic X-ray unit. British Journal of Radiology. 1993;66:150-154. Available from: https://doi. org/10.1259/0007-1285-66-782-150

20. NascimentoM,FrèreA,GermanoF.AnAutomaticCorrection Method for the Heel Effect in Digitized Mammography Images. J Digit Imaging. 2008;21(2)177-187. Available from: https://dx.doi.org/10.1007\%2Fs10278-007-9072-1 
21. Oliveira $P$, Squair $P$, Nogueira $M$, da Silva T. Uniformity and field size of filtered x-ray beams. International Nuclear Atlantic Conference. 2007; Associação Brasileira de Energia Nuclear. Available from: https://www.ipen.br/ biblioteca/cd/inac/2007/pdf_dvd/E02_1424.pdf

22. Karami V, Zabihzadeh M, Shams N, Gholami M. Evaluation of the anode heel effect on the testes dose during pelvic radiography. Tehran Univ Med J. 2017;75(2)113-119. Available from: https://tumj.tums.ac.ir/browse.php?a_ id $=8037 \&$ sid $=1 \&$ slc_lang $=$ en

23. Lai Z, dos Reis C, Sun Z. Effective dose and image optimisation of lateral lumbar spine radiography: a phantom study. Eur Radiol Exp. 2020;4(13). Available from: https://dx.doi.org/10.1186\%2Fs41747-019-0132-3
24. Davey E, England A. AP versus PA positioning in lumbar spine computed radiography: Image Quality and Individual Organ Doses. Radiography. 2015;21(2)188-196. Available from: https://doi.org/10.1016/j.radi.2014.11.003

25. Gharehaghaji N, Khezerloo D, Abbasiazar T. Image Quality Assessment of the Digital Radiography Units in Tabriz, Iran: A Phantom Study. J Med Signals Sens. 2019;9(2)137142. Available from: https://dx.doi.org/10.4103\%2Fjmss. JMSS_30_18

26. Schaetzing R. Management of pediatric radiation dose using Agfa computed radiography. Pediatr Radiol. 2004;34(Suppl 3):S207-14. Available from: https://doi. org/10.1007/s00247-004-1271-z 